\title{
CONTOS FOLCLÓRICOS COREANOS: PERSPECTIVAS PARA UMA TRADUÇÃO COLABORATIVA NO BRASIL
}

\section{KOREAN FOLKTALES: PERSPECTIVES FOR A COLLABORATIVE TRANSLATION IN BRAZIL}

\author{
Yun Jung $\operatorname{Im}^{* 1}$ \\ Luis Carlos Girão ${ }^{* 2}$ \\ Carolina Guimarães ${ }^{* 3}$ \\ Jennifer Murari ${ }^{* 4}$ \\ Laura Torelli ${ }^{* 5}$ \\ Mariane Brito*6 \\ Natália Okabayashi ${ }^{* 7}$
}

Resumo: O presente texto pretende trazer um relato sobre o processo de tradução colaborativa realizado pelo grupo de pesquisa "Hallyu - Estudos Coreanos" (CNPq/USP) para uma coletânea de contos folclóricos coreanos. Além de acompanhar o percurso de criação e estabelecimento do grupo-embrião, formado por pesquisadores ligados ao curso de Língua e Literatura Coreana da USP, pretendemos desenvolver uma discussão sobre dois aspectos tradutológicos que residem na base dessas composições ficcionais de extremo caráter oral: as onomatopeias e as expressões idiomáticas. Movidos por um pensar crítico ainda em desenvolvimento sobre o traduzir esse gênero popular da língua coreana para a língua portuguesa, questionamos e exemplificamos as escolhas feitas por quem traduz individualmente e as possibilidades de ampliação, revisão, retradução de termos, frases e construções quando se traduz coletivamente, nas trocas com outros que traduzem uma mesma obra. Por se tratar de um projeto de tradução em andamento, revisitamos alguns passos já dados e vislumbramos horizontes no que tange às

\footnotetext{
${ }^{*}$ Universidade de São Paulo, São Paulo, Brasil, doutora em Comunicação e Semiótica e líder do grupo de pesquisa "Hallyu - Estudos Coreanos" (CNPq/USP).

E-mail: <yunim@usp.br>.

${ }^{*}$ Pontifícia Universidade Católica de São Paulo, São Paulo, Brasil, doutorando em Literatura e Crítica Literária e membro do grupo de pesquisa "Hallyu - Estudos Coreanos" (CNPq/USP).

E-mail: <luis.changmin@gmail.com>.

${ }^{*}$ Universidade de São Paulo, São Paulo, Brasil, mestra em Letras Estrangeiras e Tradução e membro do grupo de pesquisa "Hallyu - Estudos Coreanos" (CNPq/USP).

E-mail: <carolinamgms@gmail.com>.

${ }^{*}$ Universidade de São Paulo, São Paulo, Brasil, graduada em Letras Coreano e membro do grupo de pesquisa

"Hallyu - Estudos Coreanos" (CNPq/USP).

E-mail: <jennifer.nascimento@alumni.usp.br>.

${ }^{*}$ Universidade de São Paulo, São Paulo, Brasil, graduada em Letras Coreano e membro do grupo de pesquisa

"Hallyu - Estudos Coreanos" (CNPq/USP).

E-mail: <laura.torelli.lopes@alumni.usp.br>.

${ }^{*}$ Universidade de São Paulo, São Paulo, Brasil, graduada em Letras Coreano e membro do grupo de pesquisa

"Hallyu - Estudos Coreanos" (CNPq/USP).

E-mail: <mariane.brito@alumni.usp.br>.

${ }^{* 7}$ Universidade de São Paulo, São Paulo, Brasil, graduada em Letras Coreano e membro do grupo de pesquisa

"Hallyu - Estudos Coreanos" (CNPq/USP).

E-mail: <nataliatae8@gmail.com>.
} 
metodologias testadas e aplicadas pelo grupo, assim como apontamos desafios presentes no exercício de traduzir de maneira coletiva, prioritariamente focado na prática neste primeiro momento. O que apresentamos aqui é apenas um resultado parcial do que estamos ensaiando enquanto tradutores em formação na coletividade, todos com os olhares dirigidos a um título de construções poéticas tão plurais quanto quem integra o grupo, o qual servirá de base para reflexões teóricas a serem desenvolvidas futuramente.

Palavras-chave: Tradução colaborativa. Literatura coreana. Contos folclóricos coreanos.

Onomatopeia. Expressões idiomáticas.

\begin{abstract}
The main goal of this paper is to present an account of the process of collaborative translation of a collection of Korean folktales by the "Hallyu - Korean Studies" (CNPq/USP) research group. Besides showing the path for the creation and establishment of the embryo-group, formed by researchers connected to USP's Korean Language and Literature course, we intend to advance the discussion on two aspects of translation that reside in the heart of fictional written compositions with an extreme oral character: onomatopoeias and idiomatic expressions. Moved by a critical thought, still in development, on translating this Korean popular genre into Portuguese, we question and exemplify the choices made both by those who translate individually and the possibilities for amplification, revision and retranslation of terms, phrases and constructions when translating collaboratively, primarily focused in translation practice at this first stage. What we present is just a partial result of what we are preparing as translators in collective formation, towards a work of poetic construction as plural as the members of our group, which will serve as stepping stone for future theoretical reflexions.
\end{abstract}

Keywords: Collaborative translation. Korean literature. Korean folktales. Onomatopoeia. Idiomatic expressions.

\title{
Introdução
}

O grupo de tradução literária focado em contos folclóricos coreanos surgiu em fevereiro de 2019, após o VII Encontro de Estudos Coreanos, que ocorreu pela Faculdade de Filosofia, Letras e Ciências Humanas (FFLCH) da Universidade de São Paulo (USP), entre os dias 2 e 4 de outubro de $2018^{1}$ - no qual o pesquisador Luis Girão apresentou uma fala sobre as tendências recentes da literatura infantil coreana, a convite da professora e tradutora Yun Jung Im,

\footnotetext{
${ }^{1}$ VIANA, Eliete. Da tradição ao K-pop: as culturas da Coreia são apresentadas em evento na FFLCH. FFLCHUSP, 2018.
} 
organizadora do evento; e anterior à realização do III Workshop de Tradução Literária, patrocinado pelo Literature Translation Institute of Korea (LTI Korea), que ocorreu pelo Departamento de Letras Orientais (DLO) da USP entre os meses de março e junho de 2019 sob a coordenação da professora Yun Jung Im e contando com oito participantes, todos focados na tradução do conto "Castella (카스테라)”, do escritor contemporâneo Park Min-gyu². Os participantes dessa última atividade foram também os primeiros integrantes a formar o grupo de tradução, que, sob a coordenação de Yun Jung Im e Luis Girão, tinha como objetivo realizar exercícios de tradução literária com foco em narrativas breves e baseadas na cultura oral da Coreia, ou seja, na forma de contos populares ${ }^{3}$.

Sob a supervisão e indicação da professora Yun Jung Im, o grupo mudou o foco de suas ações iniciais para uma coletânea de contos populares do narrador e folclorista coreano Seo Jung-oh, intitulado provisoriamente como Nosso cento de histórias antigas (우리 옛이야기 백 가지), originalmente publicado em 1996 e reeditado em $1997^{4}$. Tínhamos, assim, um robusto corpus de trabalho. No entanto, como iremos nos deter sobre a obra mais à frente, retomemos nossa atenção à apresentação e aos objetivos do grupo de tradução.

Entre saídas e entradas de novos integrantes, o grupo manteve uma média de seis integrantes fixas desde o princípio e acolheu outras quatro novas interessadas ao longo dos seus quase três anos de atividades extraoficiais - contando, hoje, com uma média de 10 integrantes 5 . É possível afirmar que, em comum, todas as integrantes do grupo têm como objetivo trabalhar com tradução literária (seja em qual forma poética for: contos, romances, livros infantis, gibis, web-novels etc.), o que nos leva a apresentar um outro objetivo do grupo: aprender sobre a língua e a cultura coreana no processo de traduzir cada conto da coletânea. Por se tratarem de textos escritos baseados em narrativas orais da tradição, que foram sendo contadas de geração em geração ao longo de séculos, eles são fontes de aprendizado profícuo acerca das estruturas míticas e folclóricas que fundam o imaginário nas produções ficcionais coreanas hoje - logo, sobre como se escreve, cria, formula novas maneiras de contar histórias na Coreia. Sendo assim, em alguma medida, ao ter contato com esses textos de alto teor oral e cultural, as integrantes do grupo exercitam sua prática tradutória individual e coletivamente, ao passo que aprendem

\footnotetext{
2 한-브라질 수교 60주년 기념 한국문학 행사 개최. LTI Korea. [S.I.] 2019.

${ }^{3}$ COELHO, 2012, p. 21-23.

${ }^{4}$ É a partir dessa versão reeditada que os trabalhos do grupo se baseiam.

${ }^{5}$ São elas: Akemi Lee, Camila Camargo, Daniela Moraes, Jennifer Murari, Laura Torelli, Luiza Roncatto, Mariane Brito, Natália Okabayashi, Núbia Tropéia - sendo que nem todas as integrantes do grupo de tradução, necessariamente, integrem o grupo de pesquisa -, além do tradutor e revisor Luis Girão e da tradutora revisora Yun Jung Im.
} 
sobre a ancestralidade da literatura coreana - que vem ganhando cada vez mais espaço no Brasil $^{6}$

Sendo assim, é possível dizer que, além de realizar exercícios de tradução literária em grupo e aprender sobre a língua e a cultura coreana, no processo, foi sendo defendida a prática e a ética do trabalho de tradução como autoria das obras traduzidas - ainda incomum no mercado brasileiro, no sentido de essas "obras derivativas" terem seus direitos autorais assegurados. Dentro dessa lógica, quem traduz realiza seu trabalho não como quem presta serviços para uma editora e/ou conglomerado editorial, mas detém autoria e parte do produto final, da obra publicada. Nas palavras das integrantes do grupo, operamos como uma "incubadora de tradutores" de literatura coreana no Brasil.

$\mathrm{Na}$ esteira dessas ações, percebeu-se que o grupo realizava tarefas de pesquisa aprofundadas nas buscas por soluções de tradução, de vocabulário, de variantes acerca dos contos. E todas essas ações geram um aprendizado em cada integrante do grupo em seu processo individual - mais ainda quando compartilhado. Assim, a professora Yun Jung Im decidiu institucionalizar essas práticas de investigação ao criar o grupo de pesquisa "Hallyu Estudos Coreanos", em 2020, certificado pelo diretório de grupos de pesquisa do CNPq junto à USP em 2021. Dessa maneira, os objetivos do grupo, extraoficial em seu princípio, tornamse oficiais e possíveis de ampliação para pesquisas além dos contos folclóricos, além de receber novos pesquisadores que estudam o fenômeno da cultura coreana no Brasil. Essa mudança (institucionalização) funciona como alicerce para que as integrantes do grupo possam realizar suas atividades dentro e fora do projeto de tradução dos contos folclóricos - como pesquisas de iniciação científica, mestrado, doutorado e pós-doutorado, mesmo formações em caráter de extensão - e sigam produzindo resultados parciais de suas investigações - como apresentações em eventos culturais ${ }^{7}$ e acadêmicos $^{8}$, publicação de artigos, capítulos e livros, mesmo organização de eventos nacionais e internacionais - enquanto a coletânea segue em seu processo de tradução coletiva: prática e pesquisa ganham novos ares e horizontes, fortalecendo o campo de estudos sobre a Hallyu (한류), ou “onda coreana", em território brasileiro e latinoamericano.

Hoje, o objetivo do grupo de pesquisa é amplo e abrange as áreas de cultura, língua e literatura coreana, focos de ensino e pesquisa dentro do Departamento de Letras Orientais da USP, onde está alocado o único curso de graduação em Língua e Literatura Coreana do Brasil.

\footnotetext{
${ }^{6}$ Para saber mais, ler Park (2019).

7 “2020 ONE Festival do Sejong Hakdang”. Leituras apresentadas por Luis Girão e Laura Torelli. [S.I.: s. n.] 2020.

${ }^{8}$ BARCAMP de Tradutores e Intérpretes do Vale do Paraíba. Escola de Tradutores. [S.I.] 2021.
} 
Por seu turno, o grupo de tradução vem realizando, paralelamente às traduções de contos folclóricos, projetos de tradução coletiva de livros de literatura infantil e juvenil coreana para editoras brasileiras.

Nesse sentido, e para finalizar nossa introdução, achamos importante pontuar que, para o presente texto, que reflete sobre um primeiro momento do grupo, de buscas mais intuitivas de soluções tradutológicas, nosso foco estará no desenvolvimento dos trabalhos a partir de exercícios práticos - individuais e coletivos. Porém, para um futuro escrito, que melhor reflita sobre um segundo momento do grupo, pretendemos combinar exercícios práticos e teóricos de tradução para revisitar os contos já traduzidos e realizar as traduções dos contos ainda não traduzidos.

\section{Sobre a obra em questão}

Composto por 100 contos populares, logo, extremamente orais e de conhecimento público, o livro de Seo Jung-oh traz, em seu prefácio, o seguinte objetivo: apresentar e propagar histórias divertidas e saudáveis, que podem ser facilmente aceitas por pessoas de todas as idades; com forte tradição e sólida composição; que mostram bem as emoções do povo coreano $^{9}$. Sendo assim, e exatamente por se tratar de um material verbal colhido de maneira oral (nas falas e escutas), o autor teve o cuidado de, em seu processo de transformar esse mesmo material em texto escrito, reescrever ou cortar a trama quando necessário, adicionando e/ou ajustando elementos aqui e ali para criar uma nova história; preservar o tom saboroso das histórias antigas, descartando figuras de linguagem de alto "teor escrito" e dando primazia às palavras mais comuns, de alto "teor oral", exatamente para tornar a atmosfera das histórias mais amigáveis e convidativas; quando necessário, usar dialetos para realçar o "sabor" do idioma e dar protagonismo a lugares, objetos, cerimônias, postos, funções e nomes próprios ${ }^{10}$. Percebese, com isso, que esta é uma coletânea importante tanto de se traduzir para o português quanto de se publicar no Brasil, por suas múltiplas contribuições (culturais, linguísticas, literárias) aos agentes envolvidos (tradutores e leitores) nesse sistema literário ${ }^{11}$.

A partir dessa premissa, os 100 contos estão divididos em seis temáticas centrais, que são:

\footnotetext{
${ }^{9}$ SEO, 1997, p. 6.

${ }^{10}$ SEO, 1997, p. 7-8.

${ }^{11}$ CANDIDO, 2000.
} 
- Tema 1: Aventuras e milagres (모험과 기적), com 16 contos;

- Tema 2: Relações e retribuições (인 연 과 응보), com 16 contos;

- Tema 3: Sorte ao acaso (우연 한 행 운), com 15 contos;

- Tema 4: O mundo como é e lições de vida (세태 와 교훈), com 17 contos;

- Tema 5: Sabedoria e perspicácia (슬기 와 재치), com 19 contos;

- Tema 6: Sarcasmo e humor (풍자와 해 학), com 17 contos.

Vemos aqui um trabalho atento de manter nos contos da coletânea tanto as características que se mantém fixas ao longo do tempo quanto aquelas que variam a depender de escolhas editoriais de quem as reescreve - algo que ecoa com as funções constantes e variáveis do conto popular, segundo Vladimir Propp ${ }^{12}$. A pluralidade de aspectos culturais particulares que são explorados nos contos de cada tema representa uma contribuição inédita à presença da literatura coreana no Brasil ${ }^{13}$. E essa mesma pluralidade no conteúdo reflete a pluralidade nas formas com as quais o grupo vem trabalhando ao traduzir os contos.

Destacamos ainda a universalidade dos temas escolhidos pelo autor da coletânea, que são motivos tão comuns nos contos de fadas e maravilhosos, mesmo nas cantigas e causos da cultura popular brasileira, e base para a criação de experiências de leitura ricas em trocas. Nesse sentido, a chegada dessa obra em terras brasileiras entraria não apenas para os títulos de fícção baseados em cultura popular e tradição, como também poderia transitar entre os títulos de literatura infantil e literatura oral - mesmo entre obras de caráter fantástico.

\section{A tradução coletiva e colaborativa}

O princípio norteador de nossas primeiras atividades foi a seleção de um conto popular bastante conhecido no imaginário coreano - a saber, "Heungbu e Nolbu (흥부와 놀부)" -, seguida pela distribuição de variadas fontes desse conto entre duplas de integrantes - cada uma responsável por traduzir uma versão. Foram realizadas reuniões presenciais para discussão de vocabulários e trocas de impressões sobre as versões traduzidas. Nas trocas, Luis Girão se responsabilizou pela elaboração de uma versão una desse conto a partir das quatro variantes

\footnotetext{
12 Apud COELHO, 2012, p. 116-119.

${ }^{13}$ As obras coreanas clássicas, em narrativas longas, que chegaram ao território brasileiro até agora são Contos da tartaruga dourada (2017), Kim Si-Seup, e A História de Hong Gildong (2020), Heo Gyun - ambas traduzidas por Yun Jung Im e publicadas pela editora Estação Liberdade. 
traduzidas (cada uma por duas tradutoras). Aqui, já se instaurava uma maneira de traduzir coletivamente, atentando-se às opiniões, impressões e decisões de cada integrante do grupo, porém, tomando cuidado para a elaboração de uma versão una que contemplasse a todos, de algum modo - logo, também colaborativa. Esse método se provou inviável pelas agendas das integrantes, bem como pela alta quantidade de textos à disposição do revisor/editor. Contudo, chegou-se a uma versão una, que foi lida em grupo.

O método foi mudado após aderirmos à obra de Seo Jung-oh. A princípio, seriam duas tradutoras traduzindo um mesmo conto (cuja entrega é mensal), sendo posteriormente revisado pelos revisores/editores (Yun e Luis) com base no conto em coreano. Não demorou e, após alguns exercícios, esse método de tradução em duplas não vingou, levando-nos a optar pela tradução individual: uma tradutora por conto (com entrega mensal), sendo posteriormente revisado pelos revisores/editores com base no texto original.

O trabalho de revisão também leva em consideração a busca por uma certa uniformização do livro em frente à variedade de tradutoras envolvidas no projeto - essa uniformização se dá no plano da voz narrativa; no uso de certos termos que aparecem com recorrência entre os contos; assim como no estilo das construções de modo a torná-las mais sonoras no plano da leitura oral. Já que o projeto em andamento é uma coletânea de contos folclóricos realizada por um único autor, ao serem divididos entre diferentes tradutoras, ainda que exista uma uniformização nos processos de revisão e edição, é possível que os textos em português apresentem diferenças entre si, marcas autorais e tradutológicas das tradutoras. Os revisores/editores buscaram garantir uma harmonia textual entre os contos, para que eles se tornem parte de um todo. Pelo mesmo motivo, houve a necessidade de realizar uma certa padronização de alguns termos e palavras que aparecem com mais frequência nos contos, tomando o devido cuidado para entender as nuances presentes nelas e em como seus sentidos podem variar dependendo do contexto em que estão inseridas.

As dúvidas de vocabulário, nesse momento, ocorriam de maneira privada, entre tradutora e revisor/editor. Contudo, as dúvidas passaram a ser realizadas de maneira coletiva, entre tradutora e demais tradutoras, além dos revisores/editores em um grupo no aplicativo de mensagens WhatsApp. Nesse grupo, geralmente uma tradutora manda uma dúvida, explicando o seu ponto de vista, e os outros integrantes a ajudam enviando suas próprias interpretações, sugestões e também links para sites externos para apoio, gerando assim uma discussão entre todos. Aqui, o ato de traduzir acontece no coletivo e de maneira colaborativa.

Com relação às ferramentas de auxílio ao processo de tradução, quando surgem dúvidas de vocabulário, as tradutoras realizam buscas em dicionários de língua coreana online (como 
Naver e National Institute of Korean Language's Korean-English Learners’ Dictionary). Já quando surgem dúvidas sobre os contos e suas variantes, as tradutoras buscam informações em enciclopédias online sobre cultura coreana (como Encyclopedia of Korean Culture e Encyclopedia of Korean Folk Culture). Dentre as tecnologias virtuais de auxílio direto à tradução de textos longos, faz-se checagem em tradutores online (como Papago Naver e Google Translate), mas sempre utilizando o senso crítico das tradutoras em face às facilidades e também aos problemas causados por esse tipo de ferramenta.

Se a tradução individual é um trabalho reflexivo solitário e introspectivo, o processo de constante troca da tradução coletiva mobiliza as diversas perspectivas que cada uma das tradutoras tem sobre a obra e também sobre o próprio ato tradutório. Um maior número de tradutores implica em um aumento de repertórios, de soluções tradutórias, de conhecimentos linguísticos, culturais ou de mundo. Por mais que, da maneira como o grupo trabalha, haja um momento de leitura e elaboração de um primeiro rascunho de tradução que é individual, ainda assim essa fase é perpassada pelo coletivo, na medida em que dúvidas ou outros pontos de interesse vão sendo levados por cada um para o grupo como um todo. A tomada de decisão feita em conjunto é diferente (e mais rica) do que a soma de suas partes. Saber trocar essas perspectivas de modo a enriquecer a discussão numa troca proveitosa de experiências e chegar a uma conclusão como um grupo é o grande desafio da tradução coletiva.

Uma vez que o grupo possui pessoas com repertórios diferentes, pode ocorrer não apenas uma diferença de estilos como também uma preferência particular por determinados termos e expressões. Como não existe uma única forma de se realizar uma tradução, é necessário uma discussão onde cada um apresente os motivos por trás de suas escolhas, e o grupo deve escolher uma das soluções sugeridas, ou até mesmo encontrar uma outra alternativa, de forma que haja uma concordância entre os participantes. Um dos desafios encontrados é satisfazer as opiniões dos vários integrantes do grupo e harmonizar possibilidades tradutórias, não só em termos de escolha de palavras em si, mas pensando em estilos diferentes de tradução. É inevitável que ocorram discordâncias em relação à tradução em alguns momentos, afinal, cada tradutora tem seu estilo próprio. Nesses casos, é importante ouvir as opiniões de todos, e testar o que se encaixa melhor para cada tradução especificamente. Por fim, entra-se em consenso após discutir em reunião as opções disponíveis sendo que, por vezes, a decisão final acaba vindo apenas na última revisão. 


\section{Desafios tradutórios}

Durante a tradução, certas questões demandaram um cuidado especial, seja por seu íntimo relacionamento com aspectos culturais, pela dificuldade de encontrar ferramentas linguísticas similares em português ou por assumirem um papel central dada a temática e proposta do texto. Dentre essas, neste artigo ressaltam-se duas delas: as onomatopeias e as expressões idiomáticas. As onomatopeias foram escolhidas como um tópico relevante devido ao fato de que em língua coreana são uma figura de linguagem amplamente utilizada, e de maneira muito distinta da língua portuguesa. Além disso, por sua natureza marcadamente sonora, as onomatopeias imprimem ritmos ao texto coreano, sendo uma parte importante de seu estilo e apelo estético, o que demanda muita reflexão por parte de quem traduz - mesmo elementos que podem estar presentes em diferentes países, como sons de animais, podem soar e ser transcritos de formas diferentes. Quanto às expressões idiomáticas, além do fato de que são únicas a cada cultura, é importante também pensar como são centrais para o gênero em questão, histórias folclóricas e contos populares que apesar de terem sido compilados e escritos, ainda carregam em si as marcas de oralidade e de sabedoria do povo. Sendo assim, iremos nos debruçar sobre alguns dos desafios tradutórios encontrados no processo, com exemplos de adaptações para onomatopeias e expressões idiomáticas, que são representativas da obra como um todo.

Em português, onomatopeia é definida como "o conjunto de palavras cuja pronúncia pretende imitar o som natural dos ruídos produzidos por seres animados ou não" por Rosália Dutra $^{14}$, como a "formação de uma palavra pela reprodução, tanto quanto possível, do som natural ou ruído a ela relacionado" pelo dicionário Michaelis (2021), ou ainda como o "processo de formação de uma palavra cujo som imita aproximadamente o som do que significa" pelo dicionário Priberam (2021). Exemplos incluiriam termos como "miau”, “au au”, “cócoricó”, ou ainda "zumbido", "sussurro", "chacoalhar". Porém, tanto o uso como a definição desse fenômeno em língua coreana são muito mais amplos.

Segundo o Instituto Nacional da Língua Coreana (NIKL), existem aproximadamente 2900 palavras onomatopaicas no idioma, sendo que esse número leva em conta apenas as palavras que estão dicionarizadas ${ }^{15}$. Em português, não se usam muitas onomatopeias, e na literatura, é mais comum encontrá-las em obras voltadas para crianças e também em HQs.

\footnotetext{
14 DUTRA, 1997, p. 145.

15 KIAER, 2018, p. 7.
} 
Porém, na língua coreana as onomatopeias se espalham por diversos registros, tanto na oralidade quanto na escrita. Dado a sua abundância, é possível afirmar que essa ferramenta linguística tão expressiva e sonora é uma característica marcante do coreano.

Além disso, o que caracteriza uma onomatopeia em coreano é bastante diferente das definições apresentadas em língua portuguesa. Isso porque, em todas as definições em português, a ideia principal é que a onomatopeia é uma representação linguística do som. Porém, em coreano, as onomatopeias vão muito além disso, incluindo também representações visuais, sensoriais, ou de outros efeitos mecânicos ou condições dinâmicas ${ }^{16}$. Em coreano, existe até mesmo uma onomatopeia para a ação de alguém hesitar, o que é estranho do ponto de vista da língua portuguesa, pois algo assim não possui som.

O vocabulário onomatopaico coreano pode ser dividido em dois grandes grupos: o primeiro é "의성 어”, ou as palavras que imitam sons; o segundo é "의태 어”, as palavras que imitam imagens ou movimentos ${ }^{17}$. Alguns exemplos do primeiro caso são "땡 땡” [ttengtteng], o som da campainha, ou “뀰꺽” [kkulkkeok], o barulho de engolir algo com força. Quanto ao segundo caso, dois exemplos são as palavras 반짝반짝 [banjjakbanjjak], que descreve a ação de algo que brilha, cintila, e 엉 금엉 금 [eonggeumeonggeum], que descreve a ação de se mover muito devagar.

Além disso, outra distinção importante na classificação das onomatopeias coreanas é o uso das vogais. As vogais $+[a]$ e $\perp[o]$ são consideradas vogais claras, e por isso expressam sentidos mais leves. Já as vogais † [eo] e $T[u]$ são consideradas escuras, expressando sentidos mais pesados ${ }^{18}$. Eis alguns exemplos citados por Jieun Kiaer ${ }^{19}$ :

\begin{tabular}{|c|c|}
\hline $\begin{array}{l}\text { Vogais claras } \\
\quad \vdash[a] \mathrm{e} \perp[o]\end{array}$ & $\begin{array}{l}\text { Vogais escuras } \\
\dashv[e o] \text { e } T[u]\end{array}$ \\
\hline $\begin{array}{l}\text { 깡총 [ggangchong]: como um coelho saltita } \\
\text { de maneira delicada }\end{array}$ & $\begin{array}{l}\text { 껑 충 [ggeongchung]: como um coelho pula } \\
\text { de maneira pesada }\end{array}$ \\
\hline 깜깜 [ggamggam]: escuro & $\begin{array}{l}\text { 껌 껌 [ ggeomggeom]: muito ou } \\
\text { completamente escuro }\end{array}$ \\
\hline 랄랄 [taltal]: som de passos leves & 털럴 [teolteol]: som de passos pesados \\
\hline
\end{tabular}

${ }^{16}$ ALEKSANDROVICH, 2016, p. 53.

${ }^{17}$ ALEKSANDROVICH, 2016, p. 53; KIAER, 2018, p. 7.

${ }^{18}$ KIAER, 2018, p. 10.

${ }^{19}$ KIAER, 2018, p. 10. 
Tudo isso deve ser levado em conta, o que certamente é um grande desafio para quem traduz o par linguístico coreano-português. A seguir, serão expostos alguns exemplos de situações desafiadoras relacionadas a onomatopeias que surgiram durante a tradução de Nosso cento de histórias antigas, assim como as estratégias que foram utilizadas para traduzi-las.

No conto "A raposa vermelha e a vovó (불여 우와 할머니)"20, surgem duas palavras que funcionam como onomatopeias: uma é “박박박박” [bakbakbakbak] e outra é o verbo “긇다” [geulkda]. “박박박박” é uma onomatopeia utilizada para indicar o som de fricção, atrito, algo sendo arranhado ou rasgado. Em coreano é utilizado uma vogal clara, mais aberta, já para o português foi pensado numa palavra que pudesse gerar um som de atrito, mais fechado. Por seu turno, o verbo “긁다” faz referência à ação de esfregar ou passar as unhas, ou um objeto pontiagudo, sobre uma superfície. Inicialmente, pensou-se na palavra “arranhar” como solução, porém, no conto esse verbo é usado para descrever uma ação feita repetidamente com as garras da raposa para retirar fragmentos de um crânio para que coubesse em sua cabeça. Sendo assim, considerou-se preferível escolher uma palavra que passasse tanto a ideia quanto o som dessa ação.

\begin{tabular}{|c|c|c|}
\hline Termo original & Discussão & Solução tradutória \\
\hline $\begin{array}{l}\text { “[...]'박박박박' } \\
\text { [bakbakbakbak] 하고 } \\
\text { 이상한 소리 가 나”21 }\end{array}$ & $\begin{array}{l}\text { Som que passe a ideia de } \\
\text { atrito, algo sendo raspado, } \\
\text { uso de uma vogal semi-aberta } \\
\text { para dar a ideia de algo mais } \\
\text { fechado }\end{array}$ & $\begin{array}{l}\text { "[...] ao som de um 'réque- } \\
\text { réque-réque' estranho." }\end{array}$ \\
\hline $\begin{array}{l}\text { “[...] 하니 사람의 } \\
\text { 해골바가지를 발톱으로 } \\
\text { 긁는데 [geulkneunde] } \\
{[\ldots] ” 22}\end{array}$ & $\begin{array}{l}\text { Ação realizada com as garras } \\
\text { de um animal que também } \\
\text { seja onomatopaica }\end{array}$ & $\begin{array}{l}\text { "O que ela [raposa] fez foi } \\
\text { raspar o fundo do crânio de } \\
\text { gente com as garras [...]" }\end{array}$ \\
\hline
\end{tabular}

No conto "A coruja cega (뉸먼 부엉 이)"23, que contém uma fábula envolvendo uma coruja, um rouxinol e uma garça representando a corrupção presente nos concursos públicos realizados durante a dinastia Joseon (1392-1897), surge uma onomatopeia que faz referência ao barulho de uma cegonha:

\footnotetext{
${ }^{20}$ SEO, 1997, p. 116-120.

${ }^{21}$ SEO, 1997, p. 117.

22 SEO, 1997, p. 117.

${ }^{23}$ SEO, 1997, p. 289-292.
} 


\begin{tabular}{|c|c|c|}
\hline Termo original & Discussão & Solução tradutória \\
\hline 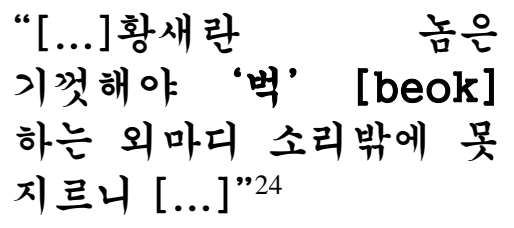 & $\begin{array}{l}\text { Ignorar a onomatopeia, } \\
\text { usando apenas o verbo } \\
\text { "guinchar" para se referir ao } \\
\text { som que a cegonha faz? }\end{array}$ & $\begin{array}{l}\text { “[...] a cegonha, fazendo o } \\
\text { seu melhor, não consegue } \\
\text { soltar mais do que um } \\
\text { guincho, 'bóóók!' [...]" }\end{array}$ \\
\hline
\end{tabular}

A princípio, cogitou-se a ideia de utilizar apenas o verbo "guinchar", sem nenhuma onomatopeia, pois o próprio verbo já carregaria uma descrição do som da cegonha. Porém, essa solução acarretaria na perda desse aspecto estilístico. Após discussão, chegou-se à conclusão de que o uso combinado do verbo "guinchar" com a onomatopeia "bóóók" deixaria claro para o leitor as características do som do animal. Assim, manteve-se a característica onomatopaica do coreano, que, exatamente por sua diferença em relação ao português, torna a experiência de leitura mais rica.

Um outro exemplo de uma outra solução possível aparece no conto "Histórias fantasma (이야기 귀신)"ㄹ, no qual um jovem prende as histórias que ouvia dentro de um saquinho, até que elas se tornam fantasmas vingativos. A onomatopeia "대 륭대 륭” [daerungdaerung], que faz referência ao movimento de algo balançando, descreve a construção verbal “달려 있다”, “estar preso". Na tradução, optou-se pelo termo "pendendo", que engloba tanto o significado da onomatopeia quanto do verbo. Além disso, a palavra "pendente", na sua combinação de sons oclusivos e nasais, remete à sonoridade da onomatopeia em coreano, colorindo dessa maneira a palavra com a sugestão do movimento.

\begin{tabular}{|c|c|c|}
\hline Termo original & Discussão & Solução tradutória \\
\hline $\begin{array}{l}\text { “[...] 먹음직스러운 } \\
\text { 배가 배나무에 } \\
\text { 대룽대룽 } \\
\text { [daerungdaerung] } \\
\text { 달려 있거든[...]”26 }\end{array}$ & $\begin{array}{l}\text { Palavra que passe a ideia } \\
\text { de algo balançando / } \\
\text { pendurado, mas que se } \\
\text { possível ainda mantenha } \\
\text { um elemento sonoro }\end{array}$ & $\begin{array}{l}\text { "[...] havia uma pera muito apetitosa } \\
\text { pendendo ao vento }[\ldots] "\end{array}$ \\
\hline
\end{tabular}

Porém, nem sempre é possível utilizar estratégias que mantenham a conotação sonora sugerida em coreano, até mesmo pelo alto número em que aparecem no idioma de partida em contraste com o de chegada. Por exemplo, no conto "Após cortar as espigas de arroz (나락

\footnotetext{
${ }^{24}$ SEO, 1997, p. 290.

${ }^{25}$ SEO, 1997, p. 66-69.

${ }^{26}$ SEO, 1997, p. 68.
} 
모가지를 끊었다가)"27, a onomatopeia “축축” [chukchuk], que indica que algo está numa posição pendente, aparece fazendo referência ao pé de arroz cuja cabeça pendia, sinal de que os grãos estavam maduros. A palavra sonora vem acompanhada do verbo “늘어지 다” (pender), o que, nesta tradução, levou-nos a optar por apenas usar o verbo, evitando uma repetição que poderia causar ruído no texto. Em apenas dois exemplos, é possível identificar a pluralidade semântica que "pender", por exemplo, traz consigo na língua coreana.

Já no conto "Filho pela Metade (반쪼가리 아들)"28, a onomatopeia “콸콸" [kwalkwal], que significa "jorrando" ou "em profusão", aparece junto com o verbo “나오다” (vir, emergir) e se refere à água que surge quando o protagonista decide cavar um poço. Em português, optouse por usar o verbo "jorrar", que conseguiria sozinho passar a imagem desejada no original. Ainda nesse conto, a onomatopeia “펄쩍펄쩍” [peoljjeokpeoljjeok], que significa pular repetidamente, aparece com o verbo “뛰다” (pular). Na tradução, a ideia de um movimento repetitivo foi mantida não com uma onomatopeia, mas com a frase "dando saltos e pulos de um lado para o outro", que também emprega uma certa sonoridade à tradução:

\begin{tabular}{|c|c|c|}
\hline Termo original & Discussão & Solução tradutória \\
\hline $\begin{array}{l}\text { “나릭이 잘 익어서 } \\
\text { 고개가 축축 } \\
\text { [chukchuk] 늘어져 } \\
\text { 있었 단 말이야." } 29\end{array}$ & $\begin{array}{l}\text { Será que é necessário } \\
\text { manter a onomatopeia que } \\
\text { acompanha o verbo, sendo } \\
\text { que a tradução desse verbo } \\
\text { para o português é capaz } \\
\text { de transmitir a mesma } \\
\text { ideia? }\end{array}$ & $\begin{array}{l}\text { "Pois a cabecinha do arrozal que } \\
\text { pendia de pesado era sinal de que } \\
\text { estava bem madura." }\end{array}$ \\
\hline 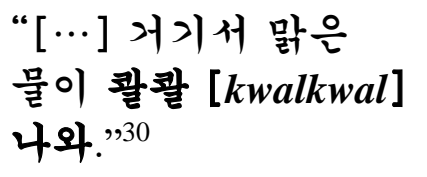 & Idem. & $\begin{array}{l}\text { "[...] água cristalina começou a } \\
\text { jorrar do buraco." }\end{array}$ \\
\hline $\begin{array}{l}\text { "[...] 수염에 불이 } \\
\text { 불어 펄쩍펄쩍 } \\
\text { [peoljjeokpeoljjeok] } \\
\text { 뛰고 [...]"31 }\end{array}$ & $\begin{array}{l}\text { A ideia de repetição e um } \\
\text { certo aspecto sonoro pode } \\
\text { ser expresso em português } \\
\text { mesmo sem o uso de uma } \\
\text { onomatopeia }\end{array}$ & $\begin{array}{l}\text { "[...] a barba chamuscada pelo fogo, } \\
\text { dando saltos e pulos de um lado } \\
\text { para o outro }[\ldots] "\end{array}$ \\
\hline
\end{tabular}

\footnotetext{
${ }^{27}$ SEO, 1997, p. 307-309.

${ }^{28}$ SEO, 1997, p. 42-45.

${ }^{29}$ SEO, 1997, p. 307.

${ }^{30}$ SEO, 1997, p. 43.

31 SEO, 1997, p. 45.
} 
É possível dizer que as escolhas de manter e/ou adaptar as onomatopeias coreanas em expressões sonoras e sensíveis às ações que elas acompanham, em língua portuguesa, foram embasadas numa atenção à construção das frases bem característica à língua de partida. Essa construção, que tem seus ritmos marcados pela entrada dessas figuras de linguagem, amplia as ações intencionadas na escritura e resguarda a oralidade de uma leitura em voz alta, mediada, performada. Enquanto expressão linguística de grande teor sinestésico, as onomatopeias que revelam, no português, uma forma de contar histórias, no coreano, trazem para o texto uma proximidade física de quem o lê, uma vez que refletem, no plano ficcional, sons e sonoridades que representam e remetem o humano e o mundo que o circunda, no plano não ficcional.

Outros desafios tradutórios que se destacaram foram os relacionados às expressões idiomáticas e provérbios. Uma expressão idiomática é definida por Claudia Maria Xatara como "uma lexia complexa indecomponível, conotativa e cristalizada em um idioma pela tradição cultural"32; já o provérbio seria "unidade léxica fraseológica fixa e, consagrada por determinada comunidade linguística, que recolhe experiências vivenciadas em comum e as formula como um enunciado conotativo, sucinto e completo, empregado com a função de ensinar, aconselhar, consolar, advertir, repreender, persuadir ou até mesmo praguejar" ${ }^{\prime 3}$. O que ambos os casos possuem em comum é sua íntima relação com a tradição cultural, além de seu alto poder de concisão e uso frequente de elementos sonoros e imagéticos; é justamente por essas características que esses termos são notoriamente considerados difíceis de traduzir.

Por exemplo, Antoine Berman ${ }^{34}$ questiona que traduções seriam possíveis para o francês de um provérbio em alemão que diz algo como "a hora da manhã tem ouro na boca". Por um lado, seria possível achar algum provérbio nativo do francês com uma moral similar, como um que diz que "o mundo pertence aos que se levantam cedo". Porém, essa tradução eliminaria toda a imagética proposta pelo provérbio alemão. Por outro lado, uma tradução mais literal e que leva em conta diversos elementos do provérbio original como imagem, sonoridade ou concisão pode funcionar, mas nem sempre é o que está em questão no texto. Para Berman, a tradução deveria então articular esses dois pólos e, dessa maneira, modificar a língua de chegada. No caso da tradução de Nosso cento de histórias antigas, estratégias diversas foram consideradas.

\footnotetext{
32 XATARA, 1998, p. 149.

33 XATARA, 2008, p. 35.

${ }^{34}$ BERMAN, 2007, p. 15-16. Tradução de Marie-Hélène Catherine Torres, Mauri Furlan e Andreia Guerini.
} 
Um exemplo, é o conto "Se comer sementes de cabaça (호박씨를 먹이 면 )"35, que fala sobre o dono de uma taberna que tenta dar um golpe em um viajante que carregava um pequeno baú. Por ter ouvido falar que comer muitas sementes de cabaça causa esquecimento, ele passa a noite toda descascando-as para servir ao viajante. Contudo, o dono da taberna é quem acaba esquecendo de cobrar pelo que o viajante consumiu e termina no prejuízo. No final do conto, surge a expressão “남잡이가 제잡이”, que transmite de maneira concisa e sonora a ideia de que aquilo de ruim que tentamos fazer aos outros acaba recaindo sobre nós. A primeira expressão a ser cogitada foi "quem o mal procura, o mal encontra", porém, essa não é uma expressão tão conhecida, além de se distanciar da narrativa. Durante a segunda revisão, discutimos a possibilidade de manter a ideia de uma ação que se volta contra quem as praticou, e que pudesse fazer um paralelo com o enredo principal do conto.

\begin{tabular}{|c|l|l|}
\hline Termo original & \multicolumn{1}{|c|}{ Discussão } & \multicolumn{1}{c|}{ Solução tradutória } \\
\hline “남잡이가 제잡이”36 & $\begin{array}{l}\text { Transmitir a ideia de que "O feitiço se vira contra o } \\
\text { "algo de ruim que se faz ao } \\
\text { outro recairá sobre você”, que } \\
\text { possua uma repetição e tenha } \\
\text { um elemento fabulesco. }\end{array}$ & \\
\hline
\end{tabular}

Já no conto "Os irmãos talentosos (재주 있는 삼형제)"37, surge uma outra expressão idiomática clássica da língua coreana:

\begin{tabular}{|c|c|c|}
\hline Termo original & Discussão & Solução tradutória \\
\hline “호랑이 담배 피을 적에”38 & $\begin{array}{l}\text { Qual o sentido desta } \\
\text { expressão idiomática? Qual o } \\
\text { papel que ela exerce no texto } \\
\text { em questão? Procurar uma } \\
\text { expressão equivalente no } \\
\text { português ou trazer a } \\
\text { expressão original para a } \\
\text { tradução? }\end{array}$ & "Nos tempos da onça" \\
\hline
\end{tabular}

\footnotetext{
35 SEO, 1997, p. 427-429.

36 SEO, 1997, p. 429.

${ }^{37}$ SEO, 1997, p. 314-316.

38 SEO, 1997, p. 314.
} 
A expressão, que diz "na época em que os tigres fumavam”, é comum de contos folclóricos e pode ter mais de uma interpretação. Ela pode indicar que se trata de uma história antiga; pode fazer referência a uma era longínqua, quando o homem vivia em harmonia com a natureza; e pode trazer por si só um elemento fantástico à história, já que tigres não fumam na vida real. Dado que, no conto em questão, a expressão aparece depois da frase "dizem que muito, mas muito tempo atrás", a ênfase está no fato de que a história se passa numa época muito distante. Durante as trocas com o grupo, outras soluções foram consideradas para a expressão, como: "dizem que muito, mas muito tempo atrás, quando os homens viviam em harmonia com a natureza e o impossível não era tão impossível assim”; “dizem que muito, mas muito tempo atrás, quando o mundo era bem diferente de como é hoje"; e "dizem que muito, mas muito tempo atrás, nos tempos da carochinha". Aqui, nos deparamos com um dilema que pode ser explicado nos termos de Friedrich Schleiermacher ${ }^{39}$ (trad. Braida, 2007) como: devemos levar o leitor ao autor, escolhendo uma tradução que explicasse o sentido da expressão, ou levar o autor ao leitor, procurando uma expressão com significado semelhante em português? Tendo decidido por procurar uma expressão equivalente na língua de chegada, a dúvida ficou entre "nos tempos da onça" e "nos tempos da carochinha". Porém, levando em consideração que a última expressão traz em si elementos muito particulares da língua portuguesa, remetendo a histórias folclóricas europeias, a solução escolhida foi a primeira. Além de trazer o sentido de "há muito tempo", a expressão contém um animal assim como a original e foi possível, dessa maneira, manter dois elementos da expressão original na tradução - o sentido e a evocação à natureza.

No conto "O genro que usava frases difíceis (문자 쓰는 사위 )" "40, o uso de expressões idiomáticas tem papel central na história, pois o protagonista só se comunica fazendo uso delas e de palavras rebuscadas. Dois exemplos desse uso são "유창자" e "지창래", que são neologismos construídos a partir de sílabas-morfemas da língua coreana, e que aparecem quando o protagonista tenta pedir ajuda aos moradores da vila para resgatar o sogro capturado por um tigre. Logo após a fala do personagem, o narrador explica de forma simplificada a mensagem dele. Sendo assim, tornou-se necessário criar, na tradução, o efeito de uma fala com termos de pouca compreensão ao público em geral para depois explicá-la com termos mais comuns. Como a língua portuguesa não aceita esses morfemas-criação da língua coreana, a solução tradutória demandou uma maior explicação, porém, com a necessidade de manter o uso

\footnotetext{
39 SCHLEIERMACHER, 2007. Tradução de Celso Braida.

${ }^{40}$ SEO, 1997, p. 459-460.
} 
de termos mais desconhecidos. Com base na Encyclopedia of Korean Folk Culture ${ }^{41}$, tem-se que "유창자" significa "possuir uma lança", enquanto "지창래" significa "ter/carregar consigo uma lança". Sendo "lança" um substantivo que provavelmente é de conhecimento de muitos leitores, optou-se pelo termo "venábulo", que seria uma antiga arma com cabo, formada por uma longa vara provida de ferro e traria o efeito de estranhamento, de algo desconhecido no discurso do personagem.

\begin{tabular}{|c|c|c|}
\hline Termo original & Discussão & Solução tradutória \\
\hline $\begin{array}{l}\text { “[ } \cdots] \text { 원산맹 호가 } \\
\text { 래오처가하야 오지장인을 } \\
\text { 착거하니 유창자는 } \\
\text { 지창래하고 유총자는 } \\
\text { 지총래 하고 유궁시자는 } \\
\text { 지궁시래하되 무창무총무 } \\
\text { 중시자는 지장래 하라. } \\
\text { 속속래 구요."42 }\end{array}$ & $\begin{array}{l}\text { Termos que expressem a } \\
\text { ideia sugerida pelos } \\
\text { morfemas que compõem as } \\
\text { palavras em coreano, mas que } \\
\text { também sejam de uso raro e } \\
\text { difícil compreensão }\end{array}$ & $\begin{array}{l}\text { "[...] Quem venábulo tenha } \\
\text { com venábulo advenha, quem } \\
\text { arma tenha com arma } \\
\text { advenha, quem arco tenha } \\
\text { com arco advenha, quem nem } \\
\text { venábulo nem arma nem arco } \\
\text { tenha com verga advenha. } \\
\text { Advenham alígeros, } \\
\text { alígeros." }\end{array}$ \\
\hline
\end{tabular}

O conto "Enquanto você corre, eu voo (뛰는 놈 위에 나는 놈)" ${ }^{43}$ conta a história de um fazendeiro que é enganado por um mercador, que lhe pede dinheiro emprestado em troca de que cuidasse de pepitas de ouro falsas. Nesse conto, o próprio título foi objeto de debate, pois traz consigo uma conotação de dito popular. A solução, nesse caso, seria adaptar essa expressão para uma que fizesse sentido em português e, simultaneamente, não perdesse a essência do coreano. Outro ponto de atenção no conto foi a expressão “발 없는 말이 천 리 간다고”, que se refere ao poder das palavras de cruzar longas distâncias. De acordo com o dicionário online Naver, a palavra "말” apresenta diversos significados, entre eles, os mais corriqueiros seriam "palavra" e "cavalo", causando um jogo de palavras na expressão original em coreano que denota tanto o movimento das palavras se espalhando, quanto o movimento da corrida de um cavalo, algo que seria intraduzível no português. Na língua de chegada, as expressões que apresentam um sentido semelhante, como "Notícia ruim corre", trazem consigo uma conotação negativa, portanto, seria necessário ponderar se essa mudança de conotação acarretaria em uma grande mudança para o texto. Visto que o trecho onde a expressão aparece fala sobre um evento ruim, embora a expressão original propriamente não demonstre isso, a princípio, seguiu-se com

\footnotetext{
${ }^{41}$ 문자 쓰다 장인 잃은 사위. Encyclopedia of Korean Folk Culture, [S.I.] [2006?].

${ }^{42}$ SEO, 1997, p. 459.

${ }^{43}$ SEO, 1997, p. 347-350.
} 
a ideia de utilizar a forma corriqueira em português, "Notícias ruins são as primeiras a chegar". Após uma última revisão, foi apontado que a expressão "Notícia não tem perna, mas corre feito cavalo" seria uma boa solução para o jogo de palavras na língua de partida, trazendo na língua de chegada a ambiguidade do termo e mantendo a intenção por trás da expressão idiomática, com tom de ensinamento.

\begin{tabular}{|l|l|l|}
\hline Termo original & Discussão & Solução tradutória \\
\hline $\begin{array}{l}\text { “뛰는 놈 위에 느는 } \\
\text { 놈”44(título) }\end{array}$ & $\begin{array}{l}\text { Traduzir literalmente "O } \\
\text { homem que voa sobre o } \\
\text { homem que corre" ou adaptar } \\
\text { para um ditado que soe bem } \\
\text { em português }\end{array}$ & $\begin{array}{l}\text { "Enquanto você corre, eu } \\
\text { voo" }\end{array}$ \\
\hline $\begin{array}{l}\text { “발 없는 말이 천 리 } \\
\text { 간다고”45 }\end{array}$ & $\begin{array}{l}\text { "Notícia ruim corre", } \\
\text { "Notícias ruins são as } \\
\text { primeiras a chegar", ou outra } \\
\text { expressão positiva? }\end{array}$ & $\begin{array}{l}\text { "Notícia não tem perna, mas } \\
\text { corre feito cavalo" }\end{array}$ \\
\hline
\end{tabular}

O conto "Histórias fantasma (이야기 귀신)" prendia as histórias que ouvia dentro de um saquinho que levava consigo e que, abafadas durante anos, essas histórias se tornaram fantasmas vingativos que planejavam assassinar seu captor no dia em que viajaria para a cerimônia de seu casamento. As três expressões destacadas foram adaptadas para um melhor funcionamento na língua portuguesa, em especial a expressão “동티 나게 요”, traduzida como "Vamos acabar encrencados". O termo original “동티” faz referência a um castigo advindo da ira dos deuses, o qual se desdobra principalmente em desastres naturais. No conto, a expressão foi empregada com o sentido de que o jovem e seu servo teriam problemas durante a viagem, caso se distraíssem com as armadilhas das histórias de fantasma pelo caminho. Portanto, uma adaptação faria mais sentido do que a tradução literal correspondente à expressão em língua coreana.

\begin{tabular}{|l|l|l|}
\hline $\begin{array}{l}\text { Termo } \\
\text { original }\end{array}$ & Discussão & Solução tradutória \\
\hline
\end{tabular}

44 SEO, 1997, p. 347.

45 SEO, 1997, p. 349.

${ }^{46}$ SEO, 1997, p. 66-69. 


\begin{tabular}{|c|c|c|}
\hline $\begin{array}{l}\text { “뭐 안다고 } \\
\text { 따라와?”" } 4\end{array}$ & $\begin{array}{l}\text { Manter o sentido original "O que } \\
\text { sabe para me seguir" ou "O que } \\
\text { pretende me seguindo"? }\end{array}$ & "O que pretende me seguindo?" \\
\hline $\begin{array}{l}\text { “동티 } \\
\text { 나게 요" } \\
(2 \mathrm{x})^{48}\end{array}$ & $\begin{array}{l}\text { Manter o sentido original "Os } \\
\text { deuses irão nos castigar" ou adaptar } \\
\text { para algo mais corriqueiro? }\end{array}$ & "Vamos acabar encrencados" \\
\hline $\begin{array}{l}\text { “죽일 놈 } \\
\text { 살릴 놈 } \\
\text { 하면서”49 }\end{array}$ & $\begin{array}{l}\text { Traduzir literalmente como } \\
\text { "Enquanto pensava se o mataria ou } \\
\text { pouparia" ou "Enquanto pensava no } \\
\text { que faria com ele"? }\end{array}$ & $\begin{array}{l}\text { "Enquanto pensava no que faria com o } \\
\text { traste" }\end{array}$ \\
\hline
\end{tabular}

É válido trazer ainda a expressão idiomática que traz um ar de praguejo no conto "Pintura que derrama aguardente (술이 나오는 그림)" ${ }^{50}$. Dentro do tema "relações e retribuições", essa é a história de um jovem lenhador que corta árvores no Monte Baekdu para ajudar a cuidar da mãe viúva adoentada e, como em todo monte nas histórias folclóricas coreanas, o elemento mágico aparece quando esse jovem se depara com um senhorzinho adoentado e precisando de ajuda. Após ajudar e salvar a vida do senhor desconhecido, o rapaz foi retribuído com uma pintura mágica como o pintor que a concebeu. No dia seguinte, a caminho do trabalho, a casa do senhorzinho havia sumido e o rapagão solta, como uma citação indireta pelo narrador: " 것ㅅ 참 이상한 일도 다 있다 하면서 나무를 했어"51. Como uma variante frasal para "그것 참 이상한 일이다" (que coisa estranha), dentro de uma expressão oral de praguejo da personagem, optou-se por uma construção também indireta, encadeada às ações seguintes, acrescentando uma marcação de espaço-tempo que faz referência ao Monte Baekdu:

\begin{tabular}{|l|l|l|}
\hline Termo original & Discussão & Solução tradutória \\
\hline "고것 참 이상한 일도 다 & $\begin{array}{l}\text { Por ser um praguejo bem comum, } \\
\text { tanto na língua coreana quanto na } \\
\text { portuguesa ("Que coisa estranha"), } \\
\text { 있다 하면서 나무를 했어"52 } \\
\text { como marcar uma diferença nesse } \\
\text { discurso indireto? Adicionamos o }\end{array}$ & $\begin{array}{l}\text { vento um 'Acontece } \\
\text { cada coisa estranha } \\
\text { por aqui', ele voltou a }\end{array}$ \\
\hline
\end{tabular}

\footnotetext{
${ }^{47}$ SEO, 1997, p. 67.

${ }^{48}$ SEO, 1997, p. 68.

${ }^{49}$ SEO, 1997, p. 68.

${ }^{50}$ SEO, 1997, p. 178-181.

${ }^{51}$ SEO, 1997, p. 179.

${ }^{52}$ SEO, 1997, p. 179.
} 


\begin{tabular}{|l|l|l|}
\hline & $\begin{array}{l}\text { localizador "por aqui" como uma } \\
\text { maneira de enfatizar que essas } \\
\text { "esquisitices" costumam acontecer } \\
\text { nos montes "mágicos" da Coreia, } \\
\text { como o Baekdu. }\end{array}$ & $\begin{array}{l}\text { cortar lenha das } \\
\text { árvores." }\end{array}$ \\
\hline
\end{tabular}

É interessante observar como as escolhas tradutórias, individuais e/ou nas trocas com o grupo, apontam para decisões que levam em conta um respeito tanto às funções plurais da língua de partida quanto ao leitor na língua de chegada. São escolhas pensadas de maneira a não perder um modo de contar em coreano, mas atentando ao modo de contar em português. Escolhas que lançam luz nas repetições e neologismos morfológicos da língua coreana, adaptando-as de maneira criativa, mas que observam também expressões próximas à língua portuguesa, com pequenos ajustes para a manutenção de um pequeno distanciamento cultural, estabelecendo estranhamentos que enriquecem a semântica corrente dessas expressões por aqui. Além disso, é válido destacar que um dos objetivos com o projeto de tradução dos contos folclóricos é tornar o texto em português apto não apenas à leitura como também à contação, ou narração oral, por mediadores e leitores dessas histórias.

\section{Considerações finais}

Uma tradução é um processo longo que demanda várias etapas de revisão, pois constantemente aprendemos algo novo que pode ser aplicado em trabalhos mais antigos. Estamos sempre nos renovando e expandindo nossos conhecimentos. A possibilidade de se trabalhar em grupo permite que todos os envolvidos possam contribuir com suas próprias experiências e pontos de vista. Traduzindo coletiva e colaborativamente, somos capazes de enxergar soluções e métodos tradutórios diferentes daqueles que estamos acostumados a fazer quando realizamos uma tradução individual. Também há a necessidade de aprender a ceder quando necessário, e reconhecer quando outra pessoa apresenta uma proposta que se adequa melhor ao que o projeto precisa. E realizar um trabalho coletivo abre espaço para criar uma tradução capaz de se comunicar com pessoas de diferentes realidades.

O grupo prevê implementar um outro método, a ser testado, que envolve duas tradutoras revisarem previamente um mesmo conto traduzido por uma terceira tradutora, sendo revisado pelos revisores/editores posteriormente - o que já configura um segundo momento do grupo, 
cujas atividades seguirão atreladas a leituras teóricas para rever práticas. A revisão coletiva, assim como da tradução, visa aprofundar os conhecimentos práticos das tradutoras, lendo traduções de outras pessoas, e contribuindo com um olhar mais distante, porém crítico e de contribuição com a versão que será revista pelos revisores/editores. O exercício de revisão, como uma das etapas futuras no projeto, visa reforçar e ampliar o escopo de formação das tradutoras que constituem o grupo.

Sendo um grupo formado majoritariamente por tradutoras iniciantes, o processo de tradução vem sendo de grande aprendizado. As trocas também são muito ricas, não apenas em relação aos debates tradutórios, mas também por conta do compartilhamento de sites com explicações culturais e de expressões idiomáticas entre os integrantes. Aprendemos não apenas sobre processos e abordagens tradutórios, mas também aprofundamos nosso conhecimento sobre a cultura coreana, principalmente levando em conta o teor dos contos traduzidos, que são folclóricos.

Este projeto é extenso e ainda demandará tempo e esforço de todos os membros do grupo, contudo, servirá para um amadurecimento para aqueles envolvidos. Percebemos que diferentes perspectivas podem agregar muito ao longo do processo e até mesmo ajudar a criar uma tradução mais rica. As discussões abertas para o grupo foram um fator crucial para esse projeto e é algo que será mantido, e essa experiência servirá de aprendizagem para futuros trabalhos.

Gostaríamos ainda de destacar o fato de o grupo de tradução ter vivenciado o processo de se tornar grupo de pesquisa, que exige outras demandas das integrantes, como ler e discutir textos teóricos, acompanhar atividades acadêmicas ligadas ao campo da tradução literária, bem como pensar em projetos individuais de pesquisa em direta conexão a projetos individuais de trabalho. Nada disso deixa de estar em circulação no coletivo, ampliando perspectivas do fazer em graus de prática e reflexão.

\section{Referências}

ALEKSANDROVICH, Okhrimenko Vitaliy. Particularities of onomatopoeic lexicon studies in modern Korean. Austrian Journal of Humanities and Social Sciences, Viena, n. 3-4, p. 53-54, 2016. 
BARCAMP de Tradutores e Intérpretes do Vale do Paraíba. Escola de Tradutores. [S.I.] 2021. Disponível em: <https://www.escoladetradutores.com.br/cursos/barcamp13.html>. Acesso em: 20 set. 2021.

BERMAN, Antoine. Tradução de Marie-Hélène Catherine Torres, Mauri Furlan e Andreia Guerini. A tradução e a letra: ou o albergue do longínquo. Rio de Janeiro: 7Letras, 2007.

CANDIDO, Antonio. Formação da literatura brasileira: momentos decisivos. 9. ed. Belo Horizonte: Itatiaia Ltda., 2000.

COELHO, Nelly Novaes. O conto de fadas: Símbolos - mitos - arquétipos. 4. ed. São Paulo: Paulinas, 2012.

DUTRA, Rosália. Discurso direto e a onomatopéia: a mímica verbal na fala cotidiana. Alfa, São Paulo, n. 41, p. 141-169, 1997.

KIAER, Jieun. The Routledge Course in Korean Translation. Nova York: Routledge, 2018.

ONOMATOPEIA. In: Dicionário Priberam da Língua Portuguesa. Disponível em: $<$ https://dicionario.priberam.org/onomatopeia>. Acesso em: 23/09/2021.

ONOMATOPEIA. In: Michaelis Dicionário Brasileiro da Língua Portuguesa. Disponível em: $<\mathrm{https}$ ://michaelis.uol.com.br/busca? $\mathrm{r}=0 \& \mathrm{f}=0 \& \mathrm{t}=0 \&$ palavra=onomatopeia $>$. Acesso em: 23/09/2021.

PARK, Yun Jung Im. A Literatura coreana no Brasil: quadro atual e desafios. Revista Criação \& Crítica, São Paulo, v. 1, n. 4, p. 4-17, 2019.

SCHLEIERMACHER, Friedrich E. D. Tradução de Celso Braida. Sobre os diferentes métodos de traduzir. Princípios, Natal, v. 14, n. 21, p. 233-265, 2007.

SEO, Jung-oh. 우리 옛이야기 백 가지 1 [Uri Yesiyagi Baekgaji 1]. 2nd ed. Seoul: Hyeonamsa, 1997.

VIANA, Eliete. Da tradição ao K-pop: as culturas da Coreia são apresentadas em evento na FFLCH. FFLCH-USP, 2018. Disponível em: 〈https://www.fflch.usp.br/956>. Acesso em: 20 set. 2021.

XATARA, Claudia Maria. O campo minado das expressões idiomáticas. Alfa, São Paulo, , n. 42, p. 147-159, 1998. 
Revisitando o conceito de provérbio. Revista de Estudos Linguísticos Veredas, Juiz de Fora, v. 12, n. 1, p. 33-48, 2008.

“2020 ONE Festival do Sejong Hakdang”. Leituras apresentadas por Luis Girão e Laura Torelli. [S.I.: s. n.] 2020. 1 vídeo (34m). Publicado pelo canal Centro Cultural Coreano no Brasil. Disponível em: 〈https://youtu.be/dr_9J3NccEY?t=819>. Acesso em: 20 set. 2021.

한-브라질 수교 60주년 기념 한국문학 행사 개최. LTI Korea. [S.I.] 2019. Disponível em: <https://www.ltikorea.or.kr/kr/pages/event/eventView.do?eventIdx=4457>. Acesso em: 20 set. 2021.

문자 쓰다 장인 잃은 사위. Encyclopedia of Korean Folk Culture. [S.I.] [2006?]. Disponível em: <https://folkency.nfm.go.kr/kr/topic/detail/5813>. Acesso em: 20 set. 2021. 